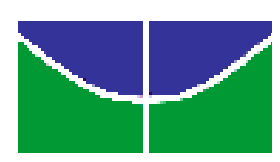

Universidade de Brasília - UnB

Faculdade de Economia, Administração,

Contabilidade e Ciência da Informação e Documentação - FACE

Programa de Pós-Graduação em Administração - PPGA

SISTEMA DE PLANEJAMENTO INSTITUCIONAL DA UNIVERSIDADE DE BRASÍLIA: UMA ANÁLISE NO PLANO ANUAL DE ATIVIDADES

ORLANDINA DE ALMEIDA FANTAUZZI

Brasília - DF 2009 


\title{
SISTEMA DE PLANEJAMENTO INSTITUCIONAL DA UNIVERSIDADE DE BRASÍLIA: UMA ANÁLISE NO PLANO ANUAL DE ATIVIDADES
}

\begin{abstract}
Monografia apresentada ao Programa de Pós-Graduação em Administração da Faculdade de Economia, Administração, Contabilidade e Ciência da Informação e Documentação - FACE, da Universidade de Brasília, como parte dos requisitos para obtenção do título de Especialização em Desenvolvimento Gerencial: Gestão Universitária.
\end{abstract}

Orientadora: Prof ${ }^{a}$. Dra ${ }^{\text {a }}$. Marilde Loiola de Menezes

ORLANDINA DE ALMEIDA FANTAUZZI

Brasília - DF

2009 


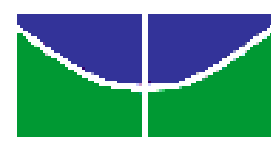

Universidade de Brasília - UnB

Faculdade de Economia, Administração, Contabilidade e Ciência da Informação e Documentação - FACE

Programa de Pós-Graduação em Administração - PPGA

SISTEMA DE PLANEJAMENTO INSTITUCIONAL DA UNIVERSIDADE DE BRASÍLIA: UMA ANÁLISE NO PLANO ANUAL DE ATIVIDADES

ORLANDINA DE ALMEIDA FANTAUZZI

Comissão Examinadora

Professora Doutora Marilde Loiola de Menezes

(Orientadora)

\section{Professor Doutor Paulo Nascimento}

(Membro) 


\section{AGRADECIMENTOS}

Ao Deus único e verdadeiro, fonte de toda a vida e companheiro fiel de todas as horas;

À Orientadora e Professora, Marilde Loiola de Menezes, pelo inestimável suporte acadêmico e profissional. Pela atenção e dedicação em opinar e sugerir novos caminhos com entusiasmo e brilhantismo. Ajudou-me a desbravar caminhos no mundo do conhecimento.

Ao Professor Paulo Nascimento, pela atenção e apoio.

À Universidade de Brasília, instituição na qual eu sou servidora, pela oportunidade a mim dada.

À servidora e colega de trabalho, Nair Miranda, pelas informações prestadas.

As amigas Lionete e Odalva, pelo apoio e carinho concedidos nesta jornada.

Aos colegas de trabalho dos institutos, faculdades e secretarias pela atenção, gentileza e ajuda na realização deste trabalho.

À Vera (Secretária do curso), pela atenção e apoio.

Meus sinceros agradecimentos. 
"Todas as idéias provêm da sensação ou da reflexão. Suponhamos, pois que a mente é, como dissemos, um papel em branco, vazio de todos os caracteres, sem quaisquer idéias. Como vem a ser preenchida? Como lhe vem esse vasto estoque que a ativa e ilimitada fantasia humana pintou nela com uma variedade quase infinita? Como Ihe vem todo $o$ material da razão e do conhecimento? $A$ isso respondo com uma palavra: pela experiência. É nessa experiência que está baseado todo o nosso conhecimento, e é dela que, em última análise, o conhecimento é derivado. Aplicada tanto aos objetos sensíveis externos quanto às operações internas de nossa mente, que são por nós mesmos percebidas e refletidas, nossa observação sempre supre nosso entendimento com todo o material do pensamento. Essas são as duas fontes de nosso conhecimento, das quais jorram todas as idéias que temos ou que podemos naturalmente ter..."

(John Locke 1632-1704) 


\section{RESUMO}

O presente trabalho visa analisar o Sistema de Planejamento Institucional da Universidade de Brasília, especificamente o Plano Anual de Atividades, tendo como objetivo verificar o nível de operacionalidade desse plano do ponto de vista das unidades acadêmicas.

Palavras chaves: Planejamento, Orçamento, Controle 


\section{1 - INTRODUÇÃO}

A conscientização cada vez maior das organizações quanto ao seu planejamento estratégico é um item que se deu especial atenção nesse contexto.

Desde o início de sua implantação, a Universidade de Brasília buscou desenvolver planos que, apesar do seu importante significado de contribuição para as unidades gestoras, não conseguiu envolver toda a comunidade universitária em suas propostas.

Após entendimento de tais situações, a UnB empenhou-se nos últimos três anos na estruturação, implantação e reavaliação permanente de um novo sistema de planejamento que, embora restrito às discussões materiais a que estão submetidas à instituições públicas, despertasse a sua capacidade de implementação e implantação de seus dirigentes e idealizadores, tanto no presente como no futuro.

Nesse sentido, torna-se cada vez mais necessário uma participação de gestores e técnicos na elaboração do Plano de Desenvolvimento Institucional da FUB, bem como a realização de criticas sempre bem aceitas por toda comunidade acadêmica.

Será que todos os que trabalham com o Plano de Desenvolvimento Institucional da Universidade de Brasília, têm consciência do que implica executar um plano autenticamente estratégico?

Foi pensando em contribuir com o aperfeiçoamento do sistema de planejamento institucional que tivemos a idéia de absorver os conhecimentos já desenvolvidos pelos idealizadores da Universidade, a fim de verificar a qualidade dessas informações tendo como público alvo as unidades acadêmicas. 
Trata-se de uma proposta a ser melhorada e ainda mais explorada. $\mathrm{O}$ assunto é demonstrar que, com flexibilidade, é possível adotar métodos e procedimentos na melhoria de relatórios oriundos das unidades acadêmicas.

Uma contribuição que julgamos de fundamental importância para a Universidade de Brasília foram os instrumentos de trabalho que permitiram aos gestores universitários, superar suas históricas desconfianças sobre a eficácia, a eficiência e a opção técnica de dar início ao processo de planejamento. A partir desse momento iniciou-se a captação das informações junto às unidades para a estruturação do sistema de planejamento.

Cabe destacar que a proposta básica dos instrumentos de planejamento do sistema de planejamento da UnB é demonstrar, com clareza e ênfase suas etapas desde o planejamento estratégico até o operacional.

Com base em cada etapa, é possível situar as definições estratégicas no Plano de Desenvolvimento Institucional (PDI), as ações e os projetos detalhados pelas unidades, bem como os seus elementos físicos e financeiros, no Plano Qüinqüenal (PQ) e no Plano Anual de Atividades (PAA).

Esse último dependerá das necessidades e dos objetivos de cada unidade. Nessa etapa, a participação das unidades gestoras juntamente com seus técnicos na elaboração do relatório trimestral é essencial para consolidar as ações desenvolvidas que levarão á construção de um diagnóstico correto da realidade, garantindo a uniformidade e a transparência nas informações da Instituição. 


\subsection{Justificativa}

No auge das incertezas sobre a política e a economia do país no curto e médio espaço de tempo, as organizações juntamente com os seus gestores estão buscando cada vez mais, compreender de forma prática e objetiva as diversas maneiras de solucionar problemas.

Em janeiro de 2002, foi implantado o novo sistema de planejamento da Universidade de Brasília que deu início á construção de um novo sistema de gestão institucional. Trata-se do Plano de Desenvolvimento Institucional que garante à Universidade, alcançar a médio prazo as condições básicas para o pleno exercício da autonomia.

É sabido de toda Unidade acadêmica da UnB, que diversos trabalhos já foram elaborados sobre o PDI - Plano de Desenvolvimento Institucional, porém, acredita-se que, por ser um assunto tão restrito para alguns, a cada nova abordagem é possível obter-se novos e mais intensos parâmetros de compreensão que venha a complementar sobre as informações já existentes, de uma forma mais compreensível, objetiva e pratica.

\subsection{Metodologia}

A metodologia utilizada para a condução do estudo foi um apanhado do conhecimento sobre o tema proposto, com visão sintética dos trabalhos de diversos autores, incluindo suas principais contribuições na área.

Metodologicamente este trabalho amparou-se em um estudo exploratório que teve como base a pesquisa documental efetuada em documentos oficiais da Universidade, para o resgate histórico do Sistema de Planejamento Institucional da UnB.

Recorreu-se, também à pesquisa bibliográfica em livros, dicionários, manuais de planejamentos, internet, objetivando a construção de uma visão 
abrangente dos aspectos teóricos e conceituais sobre Planejamento, Planejamento Estratégico, Tático e Operacional.

O instrumento utilizado para a coleta de dados foi entrevista informal, conduzida de forma espontânea.

\subsection{Desenvolvimento do trabalho}

A introdução analisa o Sistema de Planejamento Institucional da Universidade de Brasília, mais especificamente o Plano Anual de Atividades do chamado Plano de Desenvolvimento Institucional (PDI), instrumento identificado pelos planos detalhados anualmente, bem como suas metas em cada projeto elaborado. Assim, a partir da análise e compreensão do PAA, busca-se compreender o papel das unidades acadêmicas, com o objetivo de investigar se o seu nível de operacionalidade junto aos seus usuários deve ser compreendido como uma importância fundamental para o êxito e transparência de um plano estratégico.

No segundo, apresenta o referencial teórico do planejamento. No terceiro capítulo, busca-se compreender o sistema de planejamento da Universidade de Brasília e suas mudanças ocorridas durante o processo de implantação, situando suas definições estratégicas em cada plano.

O quarto e o último, trata-se da gestão das unidades acadêmicas, da participação dos gestores e colaboradores no sistema de planejamento e de algumas características indispensáveis ao seu planejamento. A análise é elaborada a partir da reflexão sobre as referidas questões. 


\section{REFERENCIAL TEÓRICO}

O processo de planejamento pode ser tão importante quanto o plano que emerge. O planejamento encoraja a administração a pensar sistematicamente no que aconteceu no que está acontecendo e no que acontecerá. Ele força a empresa, a definir melhor os seus objetivos e políticas, leva a uma melhor coordenação de seus esforços e oferece padrões de desempenho mais claros para controle (KOOTLER, 2003).

Antes de apresentar as definições de planejamento, no entender de Margarida Kunsch é preciso considerá-lo, sobretudo, como um modo de pensar sobre determinada situação ou realidade, como um processo racional-lógico, que pressupõe estudos, questionamentos, diagnósticos, tomadas de decisões, estabelecimento de objetivos, estratégias, alocação de recursos, cursos de ações etc. (KUNSCH,1970). Para a autora o planejamento seria "Algo que fazemos antes de agir, isto é, tomada antecipada de decisão". (Ackoff, apud Kunsch, 2003: 205).

Kunsch define ainda o planejamento como sendo um processo permanente e metódico de abordagem racional e científica de questões que se colocam no mundo social. Enquanto processo permanente supõe ação contínua sobre um conjunto dinâmico de situações em um determinado momento histórico.

Trabalhando o planejamento numa dimensão social, Myriam V. Baptista, ao abordar sua racionalidade, afirma:

O termo "planejamento", na perspectiva lógico-racional, refere-se ao processo permanente e metódico de abordagem racional e científica de questões que se colocam no mundo social. Enquanto processo permanente supõe ação contínua sobre um conjunto dinâmico de situações em um determinado momento histórico. Como processo metódico de abordagem racional e científica, supõe uma seqüência de atos decisórios, ordenados em 
momentos definidos e baseados em conhecimento teóricos, científicos e técnicos.(Baptista, 2000:13, apud Kunsch, 2003:207).

Mesmo considerando os cuidados no processo de formulação do planejamento, a autora chama atenção que a previsão corresponde a uma percepção provável do que possa ocorrer, isto é, uma projeção que tende a se basear em situações do passado para prognosticar o futuro. Tal "predição" como qualifica a autora, indica apenas um futuro diferenciado para situações determinadas sem, no entanto, conter elementos de controle

seguro na solução de problemas de caráter imediatismo e transitório. Plano e projeto seriam, dessa forma, instrumentos materiais do processo do planejamento sem se constituir em certezas absolutas. (2002, p. 35, apud Kunsh, 2003, p. 204).

O planejamento, pressupõe dessa forma, imagens do futuro e a definição de que a organização deve seguir no contexto desse futuro, ao passo que a solução de problemas é imediatista e visa simplesmente corrigir descontinuidades entre a organização e seu ambiente". (José Maria Dias, 1982, p. 19, apud Kunsch, 2003, p. 204).

A partir desse entendimento, o autor explora o planejamento como um processo complexo e abrangente e que possui dimensões e características próprias. Nesse sentido é que ele implica uma filosofia e políticas definidas e é direcionado por princípios gerais e específicos. Não é algo "solto" e isolado de contextos, está sempre vinculado a situações e realidades da vida de pessoas, grupos e das mais diversas organizações e instituições da esfera pública e privada. (Kunsch, 2003: 204).

O ato de planejar não se limita, portanto, a somente fazer previsões, projeções e predições na resolução de problemas ou na preparação automática de planos e projetos. Conforme Djalma Oliveira, tais acepções não condiz com o real significado do que seja planejar. 
Entendemos, dessa forma, que o planejamento seria uma espécie de trabalho de preparação para qualquer empreendimento, segundo roteiro e métodos determinados. Isso inclui "a elaboração por etapas, com bases técnicas (...), de planos e programas com objetivos definidos. (...)". (Dicionário Aurélio).

Nesse processo de definição de objetivos, ou resultados a serem alcançados, bem como os meios para atingí-los, para Maximiano, o trabalho de preparação para qualquer empreendimento se define como um "O processo de interferir na realidade com o propósito de passar de uma situação conhecida para outra situação desejada, dentro de um intervalo definido de tempo."É tomar no presente decisões que afetam o futuro, visando reduzir sua incerteza". (Maximiano, 1995: 197).

Para compreender a natureza essencial do planejamento, de acordo com Harold Koontz e Cyril O’Donnell (1982, pp. 86-7) e Djalma Oliveira (2002, pp. 37-8), é preciso levar em consideração quatro princípios básicos: a contribuição aos objetivos, a função de precedência, a abrangência e a eficiência dos planos.

Em relação a contribuição aos objetivos, O'Donnel pondera que 0 planejamento desempenha um papel fundamental na obtenção dos objetivos totais;

A função de precedência, por sua vez, indica que o planejamento precede as demais funções administrativas (organização, direção e controle), pois, embora essas funções se interpenetrem, o planejamento é que estabelece os objetivos e os parâmetros para o controle de todo o processo administrativo.

Quanto a função de abrangência, o autor chama atenção de que o planejamento exerça influência generalizada em todas as atividades da organização, provocando modificações necessárias no que tange aos recursos 
que estão sendo empregados, incluindo humanos, técnicos e tecnológicos e no sistema funcional como um todo.

Considerando o planejamento no cenário profissional, pode-se afirmar que é algo extremamente importante que resulta na otimização de resultados, gerindo melhor o tempo que na maioria das vezes é diminuído por conta de tantas tarefas.

Não raro é, no entanto, encontramos pessoas com dificuldade em executar o que planejou. As razões para isso são as mais variadas possíveis. Passam pela falta de confiança, podendo chegar ao perfeccionismo exagerado. Seja qual for o motivo, adiar a execução do que se planeja, sem uma razão aparente e justificável nem sempre é a melhor opção. Aliás, não é, pois pode custar caro, além do risco de comprometer o resultado1.

Com relação à execução, segundo Mosimann e Fisch (1999, p. 37):

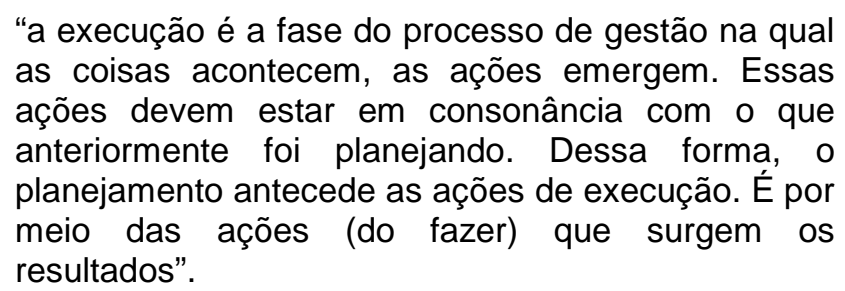

Podemos, nessa percepção, aproveitar a idéia do autor para compreender a etapa em que os planos são implementados as ações se realizam e as transações acontecem. Concluindo, é possível que ajustes ainda sejam requeridos para uma adeqüada implementação do planejamento operacional, tais como mudanças na programação e a conseqüente necessidade de identificação de novas idéias para adaptar-se às mudanças procedidas.

É de grande importância a execução das atividades nas organizações, pois é nessa etapa que os recursos são consumidos e os produtos gerados, o que valer lembrar que é exatamente nessa fase que ocorrem as mais 
significativas variações patrimoniais relacionadas às operações físicooperacionais de uma instituição.

O acompanhamento dos programas de trabalhos, juntamente com os seus indicadores e metas planejadas, requerem uma atitude prática, por parte das unidades acadêmicas, incluindo os seus usuários no processo de captação dos dados que dão origem às atividades específicas, considerando os campos de cada instrumento, no seu preenchimento.

O dado é a base para uma futura informação: "é qualquer elemento identificado em sua forma bruta que, por si só, não conduz a uma compreensão de determinado fato ou situação". (Oliveira, 2005b, p. 36).

É importante ressaltar que cada campo requer uma informação detalhada por parte de cada unidade acadêmica. Informação é o dado processado e trabalhado que permite ao executivo tomar de decisões. Ao definir informação, Oliveira comenta:

É o produto da análise dos dados existentes na empresa, devidamente registrados, classificados, organizados, relacionados e interpretados em um determinado contexto, para transmitir conhecimento e permitir a tomada de decisão de forma otimizada (2005b, p. 37).

Entretanto pela visão de alguns usuários desse sistema, tais informações deixam a desejar, impedindo o correto preenchimento dos campos.

A conectividade entre o cidadão e o processo decisório tende a se tornar cada vez mais intenso. Apesar de não ser tão perceptível às pessoas, elas se aproximam de forma séria, através da tecnologia. Não tem como escapar.

\footnotetext{
${ }^{1}$ Extraído do site http://www.soartigos.com/authors/182/SYLVIO-VIEIRA-RODRIGUES em 04/06/2009
} 
Atualmente há uma necessidade fundamental de se discutir, o fluxo de informações internas, e isso permite ao agente público estar habilitado a prestar tais informações ao público externo.

Neste contexto, vale considerar que entre funcionários, empresas e gestores existe no mundo inteiro uma relação de dependência mútua. A empresa só pode realizar sua tarefa com o auxílio de seus colaboradores de forma geral, e por isso ela depende de sua aplicação no trabalho, de seus conhecimentos e de sua disposição para obter resultados.

Outro aspecto que precisa ser considerado é que uma empresa nunca age apenas como uma instituição jurídica e econômica abstrata, mas sempre através da grande quantidade de pessoas que nela trabalham, nos diversos planos hierárquicos.

Segundo Leininger (2001, p.60), toda espécie de organização desenvolve sua vida institucional própria. Porém, isso não diminui a responsabilidade do indivíduo, só aumenta".

Para Charles Perrow, "Os critérios utilizados para divergir os diferentes tipos de organizações estão relacionados com suas funções manifestas para a sociedade, ou com a maneira pela qual elas são controladas. Ou seja, distingue-se às escolas das fábricas, ou as instituições públicas das instituições privadas" (1972, p. 50).

Kunsch faz uma diferença entre uma universidade e uma empresa industrial. Ela ressalta que a universidade é definida pelas suas funções precípuas na sociedade. Entretanto, seu modo de controle vai depender bastante das formas de propriedade pública ou privada. (2003, p. 42).

Perrow, enfatiza a tecnologia como uma variável que diferencia as características entre as organizações.

Evidentemente, as características organizacionais evoluem e passam por contínuas mudanças, já que as mesmas sofrem pressões e influências do 
ambiente onde estão inseridas e têm de se adaptar á dinâmica da história social, econômica e política para sobreviver.

Finalmente, em relação a eficiência dos planos, a indicação de O'Donnel é no sentido de atingir os objetivos minimizando os problemas e conseqüências indesejáveis.

Todos esses parâmetros devem, entretanto, ser exercidos considerando seus respectivos papeis de papéis de eficiência, eficácia e o de efetividade, que no conjunto, possibilitam maximizar os resultados e minimizar as deficiências. Eficiência, dessa forma, significa fazer bem feito de maneira adequada, com redução de custos, desempenho competente e rendimento técnico.

A eficácia liga-se a resultados em função dos quais é preciso escolher alternativas e ações corretas, usando para tanto conhecimento e criatividade para fazer o que é mais viável e certo. E a efetividade relaciona-se com a permanência no ambiente e a perenidade no tempo, no contexto da obtenção dos objetivos globais. Esses três vocábulos representam princípios fundamentais no processo de planejamento. (Kunsch, 2003, p.205). 


\section{O SISTEMA DE PLANEJAMENTO DA UNIVERSIDADE DE BRASÍLIA}

Falar de planejamento é referir-se a um campo complexo e abrangente com amplas características próprias, onde se percebe situações ou realidades como um processo racional-lógico que envolve estudos, questionamentos, diagnósticos, tomadas de decisões, estratégias, alocação de recursos, etc.

Autores como José Maria Dias, entende o planejamento como imagens do futuro que indicam caminhos ou cenários que a organização deve seguir, tendo por base as demandas sociais e competitivas, as ameaças e a oportunidades do ambiente, para que a tomada de decisões no presente traga os resultados mais eficazes possíveis no futuro. (KUNSCH, 2003, p. 214). Ao passo que a solução de problemas é imediatista e visa simplesmente corrigir descontinuidades entre a organização e seu ambiente. (DIAS, 1982:19)

Há ainda muitas outras concepções errôneas e mitos acerca do ato de planejar, como bem explica Kunsch (2003, p. 204),

\footnotetext{
"Como o de que o planejamento reduz a flexibidade, de que é uma perda de tempo administrativo, de que se trata de uma palavra mágica para todas as soluções, de que pode eliminar mudanças e impedir a tomada de decisões futuras, etc."
}

É mais ou menos consensual que, os problemas de administração das Universidades Federais Brasileiras são bastante antigos, embora a gestão dessas organizações seja uma discussão recente por ser uma gestão altamente, tradicionalista, burocrática e governamental, tem resistido a examinar com profundidade a aplicação de um novo modelo organizacional (Finger, 1997).

Embora a Universidade de Brasília, tenha sido criada na capital da república, nasceu amparada por uma fundação pública de apoio (FUB), dotada de patrimônio financeiro e imobiliário (Miranda, 2004, p.37), só veio a implantar um sistema de planejamento a partir de 1962, ou seja, quando foi definido a 
sua missão ${ }^{2}$ e objetivo ${ }^{3}$. Elaborou-se um plano orientador, passando a ser 0 primeiro instrumento de planejamento formal da Instituição.

As experiências da Universidade de Brasília em cinco décadas de existência, no que diz respeito ao planejamento estratégico, mostrou que os diferentes enfoques e práticas gerenciais, resultaram em mudanças conjunturais internas e externas à instituição.

O modo de pensar e planejar a gestão universitária resultou em uma constante melhoria e inovação da estrutura organizacional atual.

Com as mudanças ocorridas na Universidade de Brasília no que diz respeito ao crescimento discordante de suas atividades acadêmicas, prestação de serviços e existência de restrições institucionais a partir daí foi implantado um sistema integrado de planejamento estratégico, tático e operacional da Universidade de Brasília, apesar de experiências bem conduzidas iniciadas nos anos de 1993, 1998 e 2002, serem aceitas pela comunidade universitária.

Ackoff, (1978, p.3) ao fazer distinção entre planejamento tático e estratégico, afirma:

"eles são como 'cara'e 'coroa'de uma moeda podemos examiná-las separadamente, podemos até discuti-las separadamente, mas não podemos separá-las de fato".

\footnotetext{
2 (...) que contribua para a integração nacional através da ampliação das oportunidades de educação asseguradas à juventude, trazendo para seus Institutos e Escolas a mocidade de todos os Estados da Federação. É que enriqueça as modalidades de formação superior ministradas no País, contribuindo decisivamente para o preparo dos cientistas e dos técnicos, capazes de empreenderem a exploração racional do imenso patrimônio de recursos de que somos herdeiros, para colocá-lo ao serviço do desenvolvimento nacional (UnB, 1962).
}

\footnotetext{
3 (...) O documento estabelecia os seguintes objetivos para a UnB: "a) formar cidadãos responsáveis, empenhados na procura de soluções democráticas para os problemas com que se defronta o povo brasileiro na luta pelo desenvolvimento; b) preparar especialistas altamente qualificados em todos os ramos do saber, capazes de promover o progresso social pela aplicação dos recursos da técnica e da ciência; c) reunir e formar cientistas, pesquisadores e artistas e lhes assegurar os necessários meios materiais e as indispensáveis condições de autonomia e de liberdade para se devotarem a ampliação do conhecimento e à sua aplicação a serviço do homem."
}

(UnB, 1962) 
Com base em seus estudos, Gileno Marcelino considera a seguinte classificação para o tipo de planejamento e perspectivas que prevaleceram em cada uma das quatro fases de evolução dos conceitos de planejamento:

Fase 1 - Planejamento financeiro;

Fase 2 - Planejamento de longo prazo;

Fase 3 - Planejamento estratégico;

Fase 4 - Administração estratégica.

O Planejamento financeiro se referia tanto à elaboração do orçamento anual como no valor referenciado que resultava no cumprimento orçamentário. Tal abordagem era vista como uma miopia sobre a verdadeira natureza do planejamento e sua complexidade mais abrangente era desconsiderada das demais variáveis.

Quanto ao Planejamento de longo prazo, uma maior ênfase passou a ser dada à projeção das tendências e à definição dos objetivos, tendo como referência a necessidade de projetar o futuro. O principal problema resumia na rigidez dos planos formulados, deixando de lado as mudanças inevitáveis, dominadas pelas variáveis ambientais, estando sob rígido controle das organizações.

A fase de Planejamento estratégico tem como base à análise do meio ambiente, contemplando cenários e as possíveis mudanças no ambiente de negócio para desenvolver as diretrizes estratégicas.

O principal valor referencial está na preocupação de antecipar e determinar as ações futuras da organização num ambiente de incertezas e mudanças. Porém, a adoção de fórmulas simplistas tende muitas vezes a comprometer os resultados desse tipo de planejamento.

Finalmente, a Administração estratégica a sua abordagem mais atual é dada à Administração estratégica que representa a evolução do pensamento estratégico e enfatiza a adaptação, visando reduzir dependências e incertezas 
ambientais com base na orientação estratégica do próprio sistema de valores das organizações. Sua preocupação primordial é a de administrar o futuro da organização, considerando a dinâmica das turbulências ambientais. A principal dificuldade da Administração estratégica está na complexidade da coordenação de muitas variáveis ambientais.

Segundo Marcelino (1999), O Planejamento Estratégico "é um processo gerencial que possibilita ao dirigente público ou privado, estabelecer o rumo a ser seguido pela organização, com o objetivo de obter um nível de adequação entre esta e o seu ambiente".

O Planejamento estratégico diferencia-se dos planejamentos tático e operacional, pois engloba toda a organização, enquanto os outros estão relacionados com áreas específicas.

\begin{abstract}
O Planejamento Estratégico não pode ser entendido como atividade clássica de planejamento, executável por comissões ou grupos de planejamento. Ele é de responsabilidade do nível hierárquico mais alto da organização, pois tem por objetivo o alcance de resultados, através de um processo sistemático de antecipação de mudanças futuras. Analisando os pontos fortes e fracos da organização, o Planejamento Estratégico favorece 0 aproveitamento das oportunidades que aparecem e evita as ameaças externas, além de estabelecer e corrigir os cursos de ação em longo prazo (Oliveira, 2002).
\end{abstract}

Ainda com base no estudo de Nair Miranda, podemos afirmar que a análise de documentos institucionais revela que, nos anos de 1960 e 1980, foi estruturado na UnB um sistema de planejamento de natureza tática e operacional que atendia aos aspectos orçamentários e financeiros da execução das atividades acadêmicas e administrativas. 
Dessa maneira, o que se viu naquele período foi um planejamento feito em seqüências anuais, finalizando-se com a publicação de relatórios que incluíam a execução de atividades em todas as unidades acadêmicas.

Meados de 1980 - foi extinta a antiga Assessoria de Planejamento e Controle (APC), setor responsável pela condução do processo de planejamento na época. Logo após a extinção as atribuições foram encaminhadas a outros órgãos, instituídos no período.

A partir de 1990, a Universidade de Brasília, criou novamente a Assessoria de Planejamento, lembrando que em 1997, ela existiu como Secretaria de Planejamento vinculada diretamente à Reitoria.

Não se pode deixar de considerar que em meados dos anos oitenta, ocorreram diversas mudanças estruturais na área de planejamento das quais tiveram reflexo no nível de intensidade da mesma.

No entanto, devido às circunstâncias, as atividades de planejamento passaram a ser feitas de forma assistemática nas unidades de administração central, direcionadas de forma especial, ao cumprimento de exigências externas.

Em 1992, houve uma tentativa de implantação de uma proposta de planejamento estratégico na Universidade de Brasília, considerando que nesse mesmo ano, as instituições de ensino superior apresentavam dificuldades financeiras e seria necessário mudanças no sentido de buscar alternativas de desenvolvimento institucional que auxiliassem na ampliação da captação de recursos e a modernização da Universidade de Brasília (UnB, 1994).

Nos anos posteriores, com o desenvolvimento da estrutura acadêmica e administrativa, foi realizado um amplo diagnóstico institucional no planejamento estratégico, envolvendo docentes especialistas e técnicos especializados na área vinculados à Universidade de Brasília. Apesar de todo empenho dedicado, a experiência da comunidade universitária ficou limitada. 
Mediante resultados dispersos, as unidades acadêmicas começaram a questionar sobre a insuficiente articulação entre o planejamento estratégico e 0 desenvolvimento das atividades rotineiras.

No ano de 2001, o sistema de planejamento da Universidade de Brasília foi corrigido e reconhecido como sistema estratégico de gestão universitária que envolveram as unidades acadêmicas e administrativas na integração, acompanhamento e retroalimentação periodicamente, que envolveram a UnB e da FUB como atuantes no processo de acompanhamento e supervisionamento do desempenho institucional de diversas áreas.

$\mathrm{Na}$ ocasião compreendida, a adesão das unidades ao novo sistema seria de vontade própria e que a sua implantação seria a médio prazo a partir de todo envolvimento acadêmico e administrativo.

Convém destacar que o planejamento institucional abrangeria os níveis tático e operacional, além da estratégia anterior.

O processo de mudanças foram absorvidos imediatamente pela comunidade universitária, destacando a totalidade de aprovação das unidades previstas.

Participação, transparência e flexibilidade são os conceitos do novo planejamento universitário com a finalidade de buscar uma maior eficiência e eficácia administrativa e acadêmica no desenvolvimento das atividades universitárias.

Dando continuidade aos trabalhos, foram elaborados os planos iniciais das unidades que reunidos, deram origem aos três instrumentos do planejamento: 


\subsection{Plano de Desenvolvimento Institucional - PDI}

Define tanto as estratégias como as metas da Universidade a serem alcançadas a longo prazo. As estratégias assim como as metas servem de elemento orientador do planejamento institucional e como instrumento de divulgação, junto à comunidade e a órgãos externos, dos principais objetivos a serem alcançados. Deve ser aprovado pelo Conselho Universitário da UnB e pelo Conselho Diretor da FUB.

\subsection{Plano Qüinqüenal (PQ)}

Os projetos são apresentados por todas as unidades e estão associados aos objetivos e metas institucionais de longo prazo, além de serem geridos de forma institucional pelos responsáveis das dez áreas estruturadas pelo acompanhamento do planejamento a médio e longo prazos. Cabe ressaltar que os projetos e metas plurianuais das unidades são detalhados em períodos anuais permitindo o acompanhamento e replanejamento dos projetos e atividades propostos. O Plano Qüinqüenal deve ser aprovado pelas mesmas instâncias do PDI e sua operacionalização deve ser o elemento-chave na elaboração dos orçamentos anuais.

\subsection{Plano Anual de Atividades (PAA)}

Resume-se no detalhamento de objetivos e metas previstos para cada ano. Sua primeira versão é elaborada simultaneamente ao PDI e ao PQ da Instituição. Ao final de cada exercício, a avaliação e a reestruturação do PQ permitem a atualização dos Planos Anuais subseqüentes.

O PAA do primeiro exercício do Qüinqüênio é utilizado na definição da Linha de Financiamento dos projetos aprovados pelas unidades. As mudanças subseqüentes são acompanhadas pela Câmara de Administração e Finanças (CAF) da UnB. 
Pelos instrumentos apresentados, podemos destacar o Relatório Trimestral de Planejamento que além de serem cumulativos, analisam o grau de alcance das metas anuais estabelecidas pelas unidades. Nessa fase buscase o volume de recursos despendidos no desenvolvimento dos projetos elaborados, os entraves institucionais ao desenvolvimento das atividades, as medidas corretivas sugeridas pelos gestores finalistas para serem adotadas pela administração superior.

Além de permitir o acompanhamento da arrecadação das atividades desenvolvidas pelas unidades e fundações de apoio, o volume de renúncia de receita adotada pela Instituição, na realização de suas tarefas.

Todas as unidades acadêmicas sob a responsabilidade da direção, têm como parte de seu processo de gerenciamento o dever de elaborar o seu plano anual de atividades (PAA). Com base neste plano, os elementos físicos e financeiros de cada unidade serão preparados com a finalidade de atender as suas demandas globais.

O Plano Anual de Atividades (PAA) deve ser elaborado a partir do planejamento existente, com base nos objetivos, metas, orçamento, projetos e atividades, atendendo às prioridades estabelecidas.

É importante ressaltar que o sistema de planejamento da Universidade de Brasília, abrangem 3 (três) níveis. São eles: $O$ estratégico, o tático e o operacional.

Para uma melhor compreensão, a estrutura do Sistema de Planejamento da Universidade de Brasília está demonstrada no organograma abaixo. 
PLANEJAMENTO INSTITUCIONAL - 2002 - 2006

\begin{tabular}{|c|c|c|}
\hline $\begin{array}{l}\text { PLANEJAMENTO } \\
\text { ESTRATÉGICO }\end{array}$ & $\begin{array}{c}\text { PLANEJAMENTO } \\
\text { TÁTICO }\end{array}$ & $\begin{array}{l}\text { PLANEJAMENTO } \\
\text { OPERACIONAL }\end{array}$ \\
\hline \multirow{6}{*}{$\begin{array}{l}\text { QUEM? } \\
\text { REITORIA } \\
\text { DECANATOS }\end{array}$} & \multirow{8}{*}{ INSTITUTOS E FACULDADES } & \multirow{8}{*}{$\begin{array}{c}\text { INSTITUTOS E FACULDADES } \\
\text { CENTROS } \\
\text { ORGÃOS } \\
\text { COMPLEMENTARES } \\
\text { SECRETARIAS }\end{array}$} \\
\hline & & \\
\hline & & \\
\hline & & \\
\hline & & \\
\hline & & \\
\hline CONTEÚDO & & \\
\hline - MISSÃO & & \\
\hline - VALORES & \multirow{6}{*}{$\begin{array}{c}\text { CONTEÚDO } \\
\text { - OBJETIVOS } \\
\text { - METAS } \\
\text {-ORÇAMENTO } \\
\text {-PROJETOIATIVIDADES }\end{array}$} & \multirow{7}{*}{$\begin{array}{c}\text { CONTEÚDO } \\
\text { DEFINIÇÃO DAS AÇÕES } \\
\text { METAS DE } \\
\text { ACOMPANHAMENTO (FÍSICO } \\
\text { E FINANCEIRO) } \\
\text { DETALHAMENTO DE } \\
\text { ORCAMENTO } \\
\text { (ATUALIZAÇÃOIAVALIAÇÃO) }\end{array}$} \\
\hline INSTITUCIONAIS & & \\
\hline - OBJETIVOS & & \\
\hline INSTITUCIONAIS & & \\
\hline -POLÍTICAS & & \\
\hline INSTITUCIONAIS & & \\
\hline \multirow{2}{*}{$\begin{array}{c}\text { PRODUTOS } \\
\text { PDI }\end{array}$} & \multirow{2}{*}{$\begin{array}{c}\text { PRODUTOS } \\
\text { PQ }\end{array}$} & \\
\hline & & PAA \\
\hline
\end{tabular}


Subtende-se que o planejamento tático e operacional foram elaborados diretamente por Institutos, faculdades, órgãos complementares, centros e secretarias. Eles se assemelham na elaboração e diferenciam-se no conteúdo.

Dessa forma, o planejamento tático integra as ações estratégicas e táticas e abrange todas as unidades da Instituição, compreendendo o período de 5 (cinco) anos (Plano qüinqüenal).

No tocante ao planejamento operacional, é evidente que ele é considerado como formalização por meios de documentos escritos da metodologia de desenvolvimento pelas implantações, que foram estabelecidas. O horizonte temporal do planejamento operacional será anual, levando em consideração a divisão de verbas, quanto ao desempenho das unidades acadêmicas nessa etapa do planejamento (PAA).

É importante ressaltar que o plano anual de atividades da Universidade de Brasília, refere-se ao planejamento operacional, uma vez que o mesmo consta no Plano de Desenvolvimento Institucional e no plano qüinqüenal.

Nele consta o detalhamento anual para cada ano, define como a materialização prática para a realização das metas definidas no planejamento estratégico, estabelecendo as responsabilidades, recursos humanos, financeiros e materiais, bem como um cronograma de trabalho, lembrando que ele cria condições para adequadas à realização dos trabalhos diários na organização. 


\section{AS UNIDADES ACADÊMICAS E O PAA}

Em uma instituição pública ou privada o que constantemente direciona os seus objetivos são as decisões tomadas. Estas são as decisões administrativas, que, segundo Hein (1972, p.26), "são normalmente aquelas que atingem de forma imediata os objetivos de uma empresa".

Tratando-se de objetivos da empresa, é oportuno mencionar a opinião de Simon (1965, p.20) "o objetivo da organização é, indiretamente, um objetivo pessoal de todos os seus participantes". Na Universidade de Brasília, não poderia ser diferente. É necessário existir um processo relacional entre os gestores, técnicos e unidades acadêmicas para que haja sintonia com o sistema social de uma maneira global e assim propicie tanto um equilíbrio como idéias de crescimento na própria organização.

No tocante à informação, é evidente que o volume delas sobre a universidade, suas unidades e seus planos, estão acessíveis à comunidade universitária e ao público em geral. Em linhas gerais houve aumento da produtividade das unidades, principalmente das acadêmicas, o que garantiu a elevação do volume de recursos repassados à Instituição no Orçamento Geral da União.

O Plano Anual de Atividades reflete os resultados do planejamento plurianual das unidades, sendo a avaliação qüinqüenal do planejamento. É importante esclarecer que o conteúdo desse plano foi analisado e julgado nos colegiados superiores da UnB e FUB.

A Secretaria de Planejamento da Universidade de Brasília com toda a sua equipe, ocuparam nos últimos anos com a elaboração do sistema, sua implantação imediata, o nível de adesão dos gestores e as correções necessárias das propostas. No decorrer deste trabalho, fica evidente 0 processo relacional da equipe, assim como a aplicação do trabalho, sobretudo no contexto institucional. 


\subsection{A direção da unidade acadêmica}

Segundo Mintzberg (1975), o gerente desempenha papéis dentro da organização. O primeiro papel é o interpessoal, que existe como decorrência direta da autoridade e status concedidos ao gerente em função de rua posição hierárquica formal. Envolve basicamente suas relações pessoais dentro e fora da organização.

O segundo papel é o informacional, onde o gerente é colocado como centro da rede de informações.

Tal análise é fundamental, se pretendermos realmente considerar a participação e a coerência entre o debate e a prática do dia-a-dia das organizações. De nada adiantarão planejamentos excelentes se não há uma interação de ambas as partes. Considero nesta análise, tanto a administração superior, quanto os seus gestores. Acredito que o comprometimento com a Instituição de certa forma, trará bons frutos além de permitir encontrar um melhor caminho.

Sabemos que as unidades acadêmicas da UnB, precisam ser gerenciadas pelo Diretor de cada unidade. Entretanto, apesar dos seus inúmeros esforços, tanto na área de execução como na de controle, uma das maiores dificuldades se encontra justamente na falta de informações sobre o sistema de planejamento da Universidade.

Detalhar todas as atividades, projetos e programas envolvidos numa unidade acadêmica, requer um profundo conhecimento do ambiente interno e sobretudo, requer tempo. Nem todo o programa depende de um só individuo para ser desenvolvido. O tempo é curto e o sistema da própria universidade não ajuda muito para adquirir todas as informações necessárias. E o que se observa é que o controle gerencial munido de sistemas precisos, com informações relevantes é indispensável e se apresenta, portanto, como a base do desenvolvimento organizacional. 
É nesta etapa que a própria Universidade, deixa a desejar, por falta de um sistema integrado junto às unidades acadêmicas para que possa, além de garantir as informações institucionais de forma segura, agilizar á execução do trabalho. Com esse déficit, dificilmente a Universidade irá conseguir superar as dificuldades de operacionalização do planejamento.

A sugestão seria um sistema de controle gerencial mais consistente, permitindo ao gestor, por meio da interpretação dos objetivos da unidade, torná-los mais exeqüível, através do planejamento, da organização, da direção e do controle de todos os esforços realizados em todas as etapas, obtendo a sinergia necessária para atingir seus objetivos.

Fica evidente nesse pensamento que o controle gerencial passa a ser um administrador do sistema, que planeja, organiza, dirige e controla o uso dos recursos organizacionais para alcançar os objetivos da organização de maneira eficiente e eficaz.

O controle gerencial não está intimamente ligado aos problemas de gerenciamento dos recursos ou das decisões gerenciais de investimentos. No que tange a operação do sistema de empenho/compras, também deve está interligado à complexa rede sinérgica da empresa através de uma grande variedade de técnicas analíticas para a geração de respostas rápidas que permitam o gerenciamento eficaz de todo sistema empresarial.

O planejamento da organização é um processo contínuo e fundamental na rotina de trabalho onde toda a equipe em sinergia com os objetivos da empresa, sob a responsabilidade dos gestores, estabelecendo metas e determinando a melhor maneira de atingi-las.

\footnotetext{
${ }^{1}$ Extraído do site: www.viannajr.edu.br/jornal/eco
} 


\subsection{Apoio técnico na operacionalização do PAA a nível das unidades}

Didaticamente, costumam se demonstrar formas lógicas e lineares para explicar as fases do processo de planejamento. A captação das informações necessárias à implementação da primeira versão do sistema foi feita com base em três formulários simplificados que foram preenchidos por todas as unidades integrantes do Sistema de Planejamento Institucional (FUB, 2003).

O primeiro deles, planejamento estratégico, captou as informações necessárias à elaboração de um diagnóstico institucional.

O segundo, planejamento tático, apurou os projetos e metas de longo prazo, propostos pelas unidades, alinhados aos objetivos e diretrizes da Universidade. O terceiro planejamento operacional exigiu o detalhamento de cada uma das iniciativas propostas, considerando-se a sua implantação.

Pelas descrições apresentadas, podemos perceber que as principais técnicas e instrumentos empregados para a operacionalização do detalhamento das ações no Plano Anual de Atividades, estão centradas na identificação da situação a ser equacionada.

Não há como detalhar uma atividade se você não possui informação suficiente para tal. O método executivo, o plano de ataque, os recursos disponíveis devem estar bem caracterizados para garantir um bom detalhamento. Segundo Julio Candido de Meirelles Junior é necessário um escopo "fechado", um projeto básico bem definido (se possível um projeto executivo) e a participação dos profissionais ou empresas executoras. É por esta razão que o planejamento experimenta ao longo de sua "vida" um detalhamento crescente.

A informação é de fundamental importância durante a etapa do planejamento, sendo essa uma fonte de consulta que permite e possibilita conhecer antecipadamente fatores internos e externos que poderão impactar em todos os níveis que se pretende alcançar no futuro. 
De acordo com o depoimento de alguns técnicos administrativos que são os usuários do sistema de planejamento na Universidade de Brasília, principalmente na fase de execução do relatório trimestral, o processamento das informações necessárias nos devidos campos, tornam-se confusas e incompletas, pois não existe um sistema que disponibilize todos os dados correspondentes ao PDI (Plano de Desenvolvimento Institucional). Eles admitem que o sistema CONSIAFI seja falho em alguns aspectos e não que não garante um bom relatório.

Não resta a menor dúvida, de que a preparação do usuário do sistema de planejamento, propicia condições mais eficazes na sua execução. Vale destacar que a informação é um suporte indispensável para a execução do planejamento e cabe ao usuário adquiri-la de forma que se realizem os objetivos propostos.

A interação das unidades gestoras, juntamente com seus técnicos usuários do sistema, propicia horizontes significativos como um feed back fornecendo respostas sobre o que está sendo executado, configurando-se como um meio de se verificar se os objetivos planejados estão sendo alcançados.

No caso específico da Universidade de Brasília observa-se que há uma incompreensão por parte dos gestores e usuários sobre o relatório trimestral, instrumento que busca detalhar todas as informações referentes às ações e os projetos fornecidos pelas unidades acadêmicas no decorrer desse processo.

\subsection{Servidores da UnB e o Plano Anual de Atividades}

Após a etapa de planejamento inicia-se a etapa de execução, onde as coisas se desenrolam, acontecem e as ações emergem. A seqüência de ação é evidenciada no processo de controle que vem como complemento do planejamento, pois de nada adiantaria um bom planejamento sem um efetivo controle. 
O Plano Anual de Atividades é o responsável pelo detalhamento anual de todas as atividades e programas desenvolvidos nas unidades gestoras. Nele são captados os dados que dão origem aos projetos e atividades específicas. Os servidores em geral que faz parte da comunidade universitária não tem acesso ao sistema de planejamento.

Por ser um sistema informatizado da instituição, ele requer um controle através de login e senha do usuário que permite ao mesmo, entrar no sistema e assim processar todas as informações necessárias ao seu preenchimento. Neste contexto, é evidente perceber que o número de usuário é limitado, ficando a função só para os assistentes de direção das unidades acadêmicas.

Todas as atividades gerenciais e de controle são altamente prioritárias e torna-se cada vez mais relevante o profissional qualificado. A qualificação é indispensável, bem como uma formação acadêmica continuada que assegure ao profissional a capacitação suficiente para análise e tomada de decisões.

A execução necessita de um contexto de informações que propicie meios para que as atividades planejadas fluam com agilidade e segurança

Segundo, Julio Candido de Meirelles Junior, o planejamento operacional é o desdobramento do plano estratégico da empresa em ações que serão realizadas no dia a dia da organização por meio das atividades que compõem o processo de produção do bem ou serviço.

\section{Em relação a UnB}

\subsection{Professores e alunos}

A Universidade de Brasília, na condição de instituição pública tem o dever e a obrigação de prestar contas do uso de recursos públicos à comunidade universitária. É de fundamental importância, a participação da comunidade acadêmica nas decisões estratégicas da Instituição. Evidentemente isso nos leva a considerar que dentro desse conceito, insere-se professores e alunos. Participação e conhecimento nas decisões estratégicas, requer um acompanhamento através do relatório trimestral e do relatório anual, 
relatório que integra o PDI (Plano de Desenvolvimento Institucional), que segundo a Secretaria de Planejamento são divulgados no Portal da UnB (http://www.unb.br).

$\mathrm{Na}$ prática, o exercício pleno das atividades, requer um acompanhamento das diretrizes institucionais, indicadores de desempenho nas suas áreas de interesses que faz parte do sistema de planejamento institucional com base no planejamento estratégico de forma a se situar de forma institucionalmente positiva perante os conselhos universitários.

Dessa forma, a implementação desse sistema visa beneficiar professores e alunos da Universidade de Brasília.

Ao meu ver, em relação aos professores, é preciso estreitar o relacionamento entre a direção e seus colaboradores, procurando transmitir de acordo com a realidade, seus planos, projetos e programas das unidades. Para isso é preciso que a própria instituição divulgue melhor o PDI, crie um sistema integrado junto aos órgãos competentes no sentido de facilitar essas informações aos seus usuários. Creio que a aplicação dessa sugestão, só será possível em conjunto com seus órgãos de interesses ligados ao sistema de planejamento.

Dessa forma, os planos, projetos ou programas seriam melhor definidos, principalmente no planejamento anual, a exigência da qualificação profissional aos usuários do sistema para um melhor acompanhamento. 


\section{CONSIDERAÇÕES FINAIS}

Inúmeros esforços foram desenvolvidos na Universidade de Brasília para a adoção de um sistema de planejamento como meio de atender às demandas de prestação de contas dos órgãos internos e externos.

Vê-se que nas organizações públicas e privadas, o planejamento é um elemento fundamental para a sua sobrevivência. Com base nos fundamentos teóricos propostos por PETROCCHI (2001), na teoria neoclássica da administração, o planejamento posiciona-se no denominado ciclo administrativo. Isso nos leva a considerar que as funções essenciais de um planejamento são: organizar, dirigir e controlar.

Na prática, evidentemente, cada organização tem sua realidade cultural, social, política, econômica e tecnológica. Deve-se buscar uma melhor forma de ação, coordenada para cumprir sua missão e visão, preservar seus valores e atingir seus objetivos.

Nesse sentido, vale lembrar que o sistema de planejamento da Universidade de Brasília atingiu seus objetivos no tocante à definição e adoção de ferramentas necessárias à implantação de mudanças demandadas pela Instituição, correlacionados tanto com a eficiência como com a eficácia do processo administrativo e a conciliação dos recursos disponibilizados.

$\mathrm{Na}$ época de sua implementação, as técnicas e as estratégias adotadas ofereceram maior transparência à gestão universitária, bem como permitiu um acompanhamento mais preciso do uso dos recursos próprios e do tesouro no financiamento dos projetos e atividades institucionais.

No Plano Anual de Atividades, são delineados os objetivos e metas previstos anualmente. Para isso, se faz necessário elaborar sua primeira versão simultaneamente ao $P D I$ e ao $P Q$ da Instituição, lembrando que um dos 
instrumentos executados pelos usuários para o acompanhamento e avaliação do Plano Anual das Atividades é o Relatório Trimestral.

O Relatório Trimestral constitui um instrumento capaz de demonstrar o desempenho de cada unidade acadêmica da Instituição, no sentido de atender ás demandas de prestação de contas dos órgãos internos e externos que garantindo a transparência nas informações institucionais.

Devemos considerar que, embora a UnB tenha adotado um sistema de planejamento que consideravelmente procurou obedecer às circunstâncias de cenários e optou por criar e adotar novos mecanismos de gestão, não devemos esquecer que ela já teve seu modelo tradicional e a opção de definir e adotar ferramentas necessárias à sua implementação de mudanças, contribuiu para se adequar às novas exigências da sociedade contemporânea e a criar novas formas de gestão e assim se preparar e administrar melhor as incertezas e riscos no futuro, bem como se adaptar à nova realidade.

Com base no Relatório Trimestral, pode-se considerá-lo ideal para acompanhar o planejamento executado pelas unidades, em particular, bem como, pela universidade como um todo.

Entretanto são evidentes as dificuldades enfrentadas pelas unidades gestoras na elaboração do referido sistema. Isso nos permitiu, através das entrevistas que foram realizadas com cerca de 20 (vinte) Assistentes responsáveis e usuários do sistema, observar que o processamento de qualquer sistema automatizado requer além de capacidade operacional de saber operacionalizar o sistema, capacitá-los como profissionais especializados para conduzir esses instrumentos que já estão disponíveis e precisam ser melhorados.

Coletar as informações necessárias para preencher os campos é de grande importância na elaboração do Relatório Trimestral. A preparação do responsável pelo sistema é essencial, pois com as informações devidas das atividades que deverão acompanhar o relatório, possibilita preencher 
devidamente os dados, a fim de evitar distorções na interpretação das mesmas.

O ponto de estrangulamento do planejamento é quando ele chega até a ponta principal e limita o seu desempenho. Tem que haver uma integração maior entre os planejadores, consultores e aqueles que o executam.

Dessa forma, chega-se à conclusão de que, para desenvolver um relatório, condizente com as unidades acadêmicas, é preciso que a administração superior valorize este aspecto e tenha a intenção de mudar. A começar pelo ambiente interno, analisar o desempenho das atividades no diaa-dia para que o fornecimento de dados não fujam à realidade.

Adotar um sistema integrado na instituição, onde todas as informações, referente aos gastos institucionais dos programas, estejam diretamente interligados no próprio sistema, possibilitando uma importação de informes em tempo hábil na execução do referido Relatório.

Um dos aspectos abordados pela pesquisa é de que o relatório CONSIAFI, apesar de ser um sistema bom, deixa muito a desejar, devido a uma série de fatores aqui descritos por alguns entrevistados.

... "O CONSIAFI, é um sistema bom, só que o usuário tem que saber operá-lo".

... "O relatório CONSIAFI, é um tanto complicado para os usuários, devido às informações que os mesmos não conseguem captar, por se tratar de um sistema não amigável e que é mais conveniente para aqueles que exercem funções de contador, devido à sua linguagem e modelo".

... "As informações fornecidas, através do relatório CONSIAFI, são vagas, e não ajudam muito na execução do relatório trimestral. Perde-se muito tempo em operá-lo e às vezes tem que fazer o controle de gastos, indo diretamente ao setor responsável'. 
Pelas considerações apresentadas, podemos concluir que a organização deve ter consciência da importância de capacitar sua equipe técnica com orientações práticas para elaboração de um relatório. Precisam ser pensadas estrategicamente cada processo a ser definido.

Faz-se necessário sensibilizar a administração superior, os representantes das unidades acadêmicas e os responsáveis pelo uso do sistema, de que vivemos na era do conhecimento e isso implica buscar a excelência profissional. Enfim, são inúmeras as possibilidades nesse sentido, conforme já foi mencionado.

É neste campo que se deve investir, para que as transformações ocorram e que realmente venham a fazer parte do cotidiano da organização.

No contexto organizacional, cabe às unidades acadêmicas manter sempre o planejamento, a coordenação, a execução e o controle das ações de interesse da organização a partir de parâmetros e indicadores previamente estabelecidos na esfera institucional. 


\section{REFERÊNCIAS BIBLIOGRÁFICAS}

BRASIL. UNIVERSIDADE DE BRASÍLIA. Documentos para a implementação do planejamento estratégico e da avaliação institucional da UnB. Assessoria de Planejamento e Avaliação institucional/APA. UnB: Brasília, mimeo, agosto 1994.

Universidade de Brasília (UnB). Relatório de Gestão 1993/1997. texto de divulgação restrita. Brasília, mimeo, 1997.

Universidade de Brasília (UnB). Secretaria de Planejamento. Secretaria de Planejamento. Manual de Planejamento do Plano de Desenvolvimento Institucional: 2002-2006. Brasília, 2003.

ACKOFF, Russel. L. Planejamento empresarial. Rio de Janeiro : Livros Técnicos e Científicos, 1978.

ALMEIDA, Martinho. I. Ribeiro. Manual de planejamento estratégico. São Paulo: Atlas,

BAPTISTA, Myriam Veras. Planejamento Social: intencionalidade e instrumentação. São Paulo: Veras Editora 2000.

DIAS, José Maria A.M. "Planejamento organizacional: conceito e tendências". In: Vasconcelos Filho, Paulo de et al. (orgs.) Planejamento empresarial: teoria e prática. Leituras selecionadas. Rio de Janeiro: LTC, 1982.

Dicionário Aurélio da Lingua Portuguesa. Aurélio Buarque de Holanda Ferreira, Margarida dos Anjos, Marina Baird Ferreira, Elza Tavares Ferreira, Joaquim Campelo Marques, e Stella Rodrigo Octávio Moutinho, 1986, 85-209-0411-4, Editora Nova Fronteira, Novo Dicionário Aurélio da Língua Portuguesa.

FINGER, Almeri Paulo. Gestão de universidades: novas abordagens, Curitiba: Champanhat, 1997. 
FUNDAÇÃO UNIVERSIDADE DE BRASÍLIA. Plano do Desenvolvimento Institucional - PDI/FUB 2002-2006. Brasília, Janeiro de 2005.

FUNDAÇÃO UNIVERSIDADE DE BRASÍLIA. Plano qüinqüenal - PQ/FUB 2002-2006. Brasília, Janeiro de 2005.

KOONTZ, Harold; O’DONNELL, CYRIL. Princípios da Administração: Uma análise das funções administrativas. Trad. de Albertino Pinheiros e Ernesto D’Orsi. 2 V. 13를 ed. São Paulo: Pioneira, 1982.

KOTLER, Philip. Administração de Marketing: Análise, planejamento, implementação e controle. Trad. De Silton Bonfim Brandão. 3ª ed. São Paulo: Atlas, 1995.

KUNSCH, Margarida M. Krohling (Coord.) "Planejamento estratégico e excelência na comunicação". In: Kunsch, Margarida M. Krohling (org.). Obtendo resultados com relações públicas. São Paulo: Pioneira, 1997 C.

.Planejamento de relações públicas, na comunicação integrada". $3^{\text {a }}$ ed. São Paulo: Summus, 1995.

MARCELINO, Gileno. Planejamento estratégico em gestão universitária: O Caso da Faculdade de Estudos Sociais Aplicados da Universidade de Brasília. Texto apresentado no VI Congresso Internacional Del CAD (http://cebem.com/biblioteca/Vicongresoclad/marcelin.PDF).

Seminários de planejamento estratégico. Brasília: UnB/SPL, 1988.

MAXIMIANO, Antônio César Amaru. Teoria Geral da Administração: da escola científica à competitividade em economia globalizada. São Paulo, Atlas, 1997.

MEIRELLES Jr, Julio Candido de. O Controller na gestão do negócio. Revista Mineira de Contabilidade, Belo Horizonte, n. 12, p. 12-15, 4ํㅡㄴim. 2003. 
MINTZBERG, Henry; AHLSTRAND, Bruce; LAMPEL, Joseph. Safári de estratégia; um roteiro pela selva do planejamento estratégico. Trad. de Nivaldo Montingelli Jr. Porto Alegre: Bookman, 2000.

MIRANDA, Nair Aguiar. O processo de mudança na UnB: 1993-1997. Trabalho premiado no 20 Concurso Nacional de Experiências Inovadoras de Gestão do Setor Público, promovido pelo Ministério de Administração e pela ENAP http://www.enap.gov.br/html/concurso/resultado 02.htm.Brasília, ENAP, 1997.

MODELOS DE RELATÓRIOS GERENCIAIS: CONSIAFI. Decanato de Administração/DCF. UnB, 2003.

MOSIMANN, Clara Pellegrinello; Fish, Sílvio. Controladoria: Seu papel na administração de empresas. $2^{\underline{a}}$ ed. São Paulo. Atlas, 1999.

OLIVEIRA, Djalma de Pinho Rebouças de. Planejamento estratégico: a competitividade para administrar o futuro das empresas. $2^{\underline{a}}$ ed. São Paulo: Atlas, 1995.

PERROW, Charles. Análise organizacional. Um enfoque sociológico. São Paulo: Atlas, 1972.

SRH/SPL. Brasília. Versão preliminar, 2003.

\section{SITES:}

http://www.soartigos.com/authors/182/SYLVIO-VIEIRA-RODRIGUES.

Em 04/06/2009.

http://www.spl.unb.br/

http://www.viannajr.edu.br/jornal/eco.

em 04/06/2009. 
